\title{
Estrategias lúdicas para aumentar el conocimiento de un grupo de adolescentes sobre el virus del papiloma humano
}

\section{Playful strategies to increase knowledge about the human papillomavirus in a group of adolescents}

\author{
Sandra Marcela Gómez-Marín ${ }^{1}$ (D) Alexandra Agudelo-Ramírez² (D), Ányela Sofia Pradilla-Serrano(D), \\ Juliana García-Hincapié3 ${ }^{3}$
}

Tipología: Artículo de investigación científica y tecnológica

Para citar este artículo: Gómez-Marín SM, Agudelo-Ramírez A, Pradilla-Serrano AS, García-Hincapié J. Estrategias lúdicas para aumentar el conocimiento de un grupo de adolescentes sobre el virus del papiloma humano. Duazary. 2019 mayo; 16(2): 219-232. Doi: https://doi.org/10.21676/2389783X.2741

Recibido en diciembre 21 de 2017

Aceptado en octubre 22 de 2018

Publicado en línea en febrero 15 de 2019

\section{RESUMEN}

El objetivo fue formular y desarrollar un conjunto de estrategias lúdicas para aumentar el conocimiento sobre el Virus del Papiloma Humano y la vacuna en un grupo de adolescentes escolarizados en un corregimiento de Pereira, Colombia. Se utilizó metodología cualitativa con método acción-participación. Se involucraron 17 estudiantes. Como técnicas de investigación se usaron grupos focales y talleres pedagógicos; los discursos de los adolescentes fueron grabados y transcritos. Para el análisis de datos se realizó identificación de unidades de sentido, codificación y categorización. Al inicio del proyecto, los adolescentes tenían poco conocimiento sobre el Virus del Papiloma Humano, las enfermedades de transmisión sexual en general y sus manifestaciones clínicas; pero al finalizar el proceso tenían claridad sobre los órganos implicados, factores protectores, la vacuna como método preventivo y la relación del virus con el cáncer. Los adolescentes relacionaron la falta de uso del preservativo y el tener múltiples parejas sexuales como factores de riesgo para adquirir una enfermedad de transmisión sexual, especialmente el Virus del Papiloma Humano. Las estrategias lúdicas permitieron a los adolescentes generar nuevo conocimiento por medio de un proceso de interiorización, reflexión y compresión sobre el virus y la vacuna.

Palabras clave: educación sexual; infecciones por papillomavirus; adolescente; educación de la población; promoción de la salud.

\footnotetext{
1. Fundación Universitaria Autónoma de las Américas. Pereira, Colombia. Correo: marcelita_1221@hotmail.com - http://orcid. org/0000-0002-0356-8684

2. Fundación Universitaria Autónoma de las Américas. Pereira, Colombia. Correo: alexandra.agudelo@uam.edu.co - http://orcid. org/0000-0002-5858-8420

3. Fundación Universitaria Autónoma de las Américas. Pereira, Colombia. Correo: julihincapie_08@hotmail.com - http://orcid. org/0000-0002-7582-099X
} 


\section{ABSTRACT}

The purpose of this research was to formulate and develop playful strategies to increase the level of knowledge about the Human Papillomavirus and the vaccine in a group of schooled adolescents who live in a village in Pereira, Colombia. A qualitative methodology with Action-Participation method was used. They were 17 students involved. Focus groups and pedagogical workshops were used as research techniques; adolescents' speeches were recorded and transcribed. In order to analyze the data, an identification of units of meaning, coding and categorization was carried out. At the beginning of the project the adolescents had poor knowledge about the Human Papillomavirus and the sexually transmitted diseases, on top of this they were unaware of their clinical manifestations; nevertheless, at the end of the process they had clarity about the organs involved, protective factors, the vaccine as a preventive method and the relation between the virus and cancer. The adolescents identified the lack of condom use and multiple partners as risk factors for acquiring a sexually transmitted disease, especially the Human Papilloma Virus. The playful strategies allowed the adolescents to generate new knowledge through a process of internalization, reflection and understanding about the virus and the vaccine.

Keywords: Sex Education; Papillomavirus Infections; Adolescent; Health Education; Health Promotion.

\section{INTRODUCCIÓN}

a sexualidad es una característica de la vida

-de todos los seres humanos, está relacionada con la capacidad de sentir placer e involucra aspectos físicos, sentimentales y emocionales ${ }^{1}$. Esto quiere decir que se vincula con la forma de ser, pensar, sentir, actuar y relacionarse con otras personas y consigo mismo. Por lo anterior, la sexualidad constituye un pilar fundamental en el desarrollo de la personalidad durante la adolescencia, definida según el Fondo de las Naciones Unidas para la Infancia (Unicef) como la etapa que transcurre entre los 10 y 19 años de edad, en la cual se consideran dos fases: adolescencia temprana (10 a 14 años) y adolescencia tardía (15 a 19 años). En cada uno estos periodos se presentan cambios fisiológicos, estructurales y modificación en el perfil psicológico y de la personalidad ${ }^{2}$.

El inicio de las relaciones sexuales se da también en esta etapa de la vida; según el Estudio a Profundidad Basado en las Encuestas Nacionales de Demografía y Salud (ENDS 1990 - 2010), del total de mujeres sexualmente activas el $69,19 \%$ tuvo su iniciación sexual entre los 15 y 18 años ${ }^{3}$. Lo anterior revela que las adolescentes están empezando su vida sexual a edades cada vez más tempranas, lo que sumado a prácticas sexuales inadecuadas y múltiples compañeros sexuales se convierten en factores de riesgo para adquirir Enfermedades de Transmisión Sexual (ETS).

Por otra parte, la Organización Mundial de la Salud (OMS) refiere que cada día hay más de un millón de personas en el mundo que contraen una ETS ${ }^{4}$. De ahí la importancia de los conocimientos y las prácticas adecuadas sobre la sexualidad en adolescentes, ya que su deficiencia ha generado no solo problemas de ETS sino también altos porcentajes de embarazos no deseados y abortos en condiciones inadecuadas, entre otros ${ }^{5-7}$.

Según el Centro para el Control y la Prevención de Enfermedades (CDC) de Estados Unidos (EE.UU.) anualmente se reportan 20 millones de personas infectadas con alguna ETS, lo que representa un costo mayor a USD 16 billones $^{8}$. El CDC también informa que este virus es la causa de casi el 90\% de los cánceres de ano y 
cuello uterino, cerca del 70\% de los cánceres de vagina y de vulva y más del $60 \%$ de los cánceres de pene ${ }^{8}$.

La OMS afirma que el VPH es la causa de la infección vírica más común del tracto reproductivo y que la mayoría de las mujeres y hombres sexualmente activos contraerán la infección en algún momento de su vida. Este organismo menciona además que algunas personas pueden tener infecciones recurrentes y que el punto álgido para contraer la infección es poco después del inicio de la vida sexual ${ }^{9}$. Asimismo, se conoce que el VPH provoca anualmente 528.000 casos de Cáncer de Cuello Uterino (CCU) y 266.000 de las muertes en el mundo ${ }^{4}$.

En la literatura científica se encuentran estudios en los que se indaga por conocimientos sobre ETS y en algunos específicamente por VPH. Por ejemplo, en una investigación realizada en Cuba sobre los conocimientos en materia de identificación de variedades de ETS, se encontró que solo el 43,3\% de los alumnos encuestados alcanzaron buenos conocimientos, a partir de lo cual desarrollaron un programa educativo con técnicas participativas ${ }^{7}$. En Chile, en una revisión acerca de creencias y VPH, se halló que hay múltiples interpretaciones del tema y que más que creencias se podría hablar de conocimientos erróneos, por lo que las intervenciones deben involucrar no solo aspectos biológicos sino también emocionales y culturales ${ }^{10}$.

En Colombia, según la ENDS, el $44 \%$ de las mujeres entre los 13 y los 69 años ha escuchado hablar del VPH, en tanto solo la cuarta parte sabe que existen vacunas para prevenirlo, conocimiento que se incrementa en las mujeres con uno a tres hijos y en aquellas que cuentan con educación superior, de las cuales menos del 1\% se ha aplicado la vacuna ${ }^{3}$.
Hoy en día el VPH es considerado un problema de salud pública y en las mujeres se convierte en un factor preponderante para el desarrollo de $\mathrm{CCU}^{11,12}$. En Colombia, para el quinquenio 2007-2011, se estimó una tasa de incidencia para este cáncer de 18,7 por 100.000 mujeres, constituyéndose en la segunda causa de cáncer más frecuente entre la población femenina después del cáncer de mama ${ }^{13}$.

Por lo anterior, el profesional en medicina como agente de salud tiene la responsabilidad de participar activamente en acciones de prevención de las ETS y en particular del VPH. De este modo la educación para la salud toma relevancia, principalmente en estrategias dirigidas a adolescentes, pues constituyen un grupo social vulnerable a estas patologías.

El proceso de educación para la salud debe ser participativo y reflexivo e implica el uso de metodologías adaptadas a los grupos poblacionales. En este sentido, las estrategias lúdicas son consideradas eficaces para el trabajo con niños y adolescentes. Esta metodología parte de las percepciones, los saberes y experiencias previas que tienen los participantes, $y$ los vincula activamente en el proceso de aprendizaje siendo el sujeto quien construye sus propios esquemas de conocimiento. De igual modo, promueve el aprendizaje significativo, estimula la creatividad y la capacidad de generar propuestas, y no se reduce a la memorización ${ }^{14}$. Asimismo, la lúdica facilita el aprendizaje colaborativo e involucra la emocionalidad y el uso del cuerpo.

El objetivo de la investigación fue formular y desarrollar un conjunto de estrategias lúdicas para aumentar el conocimiento sobre el Virus del Papiloma Humano y la vacuna en un grupo de adolescentes de octavo grado de la Institución Educativa Carlos Castro Saavedra en el corregimiento de Puerto Caldas, municipio de Pereira en el 2016-1. 


\section{MATERIALES Y MÉTODOS}

\section{Tipo de estudio}

Se realizó un estudio de enfoque cualitativo y se empleó una postura metodológica de carácter dialógico en la que las creencias, saberes previos, actitudes y opiniones constituyeron los insumos primarios para el análisis y la generación de nuevo conocimiento. Se utilizó el método acción-participación, el cual se define como un proceso reflexivo que vincula la investigación, la acción y la formación con un grupo de trabajo; es un método participativo y de aprendizaje colaborativo que sigue una espiral introspectiva, caracterizada por ciclos que tienen momentos de planificación, acción, observación y reflexión.

El método se diseñó en cuatro fases: I) exploración y estrategia de recolección de datos sobre el nivel de conocimiento previo de los estudiantes sobre el VPH y la vacuna; II) planeación y formulación de las estrategias lúdicas en conjunto con los estudiantes; III) aplicación de las estrategias; IV) evaluación de resultados a partir del nivel de conocimiento adquirido.

\section{Población y muestra}

El muestreo fue no probabilístico a conveniencia, la muestra estuvo conformada por 17 estudiantes, ocho mujeres y nueve hombres, con edades entre los 12 y 15 años, estrato socioeconómico 1, 2 y 3 del grado $8^{\circ}-2$ de la institución educativa Carlos Castro Saavedra, ubicada en el corregimiento de Puerto Caldas del municipio de Pereira en el departamento de Risaralda, Colombia. Se excluyeron los alumnos que no firmaron el asentimiento informado y/o cuyos padres no firmaron el consentimiento informado. El grupo inicial se dividió en dos para garantizar mayor participación, uno estuvo conformado por ocho estudiantes y el otro por nueve. El trabajo de campo fue ejecutado durante el primer semestre del año 2016. El proyecto fue presentado tanto a las directivas como a los adolescentes de la institución, y de ambos actores se obtuvo la aprobación para su desarrollo. Cabe resaltar que la participación de los adolescentes fue voluntaria durante todo el proceso.

\section{Procedimiento y técnicas}

Las técnicas de investigación empleadas fueron: observación participante, grupos focales y talleres pedagógicos. Se llevaron a cabo dos grupos focales, uno inicial y uno final, para los que se elaboraron preguntas semiestructuradas acerca del VPH y la vacuna. En los talleres pedagógicos se abordaron temas como: anatomía del sistema reproductor femenino y masculino; enfermedades de transmisión sexual; manifestaciones clínicas del VPH; relación del virus con el cáncer de cuello uterino, orofarínge y ano; factores de riesgo para adquirir el VPH; creencias sobre la vacuna y factores protectores. En total se ejecutaron siete talleres pedagógicos cado uno con una duración de 90 minutos aproximadamente. También se hizo observación participante durante los talleres en los que realizaron anotaciones en diarios de campo, grabaciones y transcripciones de estas.

\section{Análisis de datos}

Una vez se registró toda la información, se comenzó el proceso de análisis e interpretación de los datos. Se identificaron las unidades de sentido de acuerdo con el conocimiento que tenían los estudiantes acerca del VPH y la vacuna, sus dudas, experiencias, opiniones y percepciones. Se agrupó, comparó y analizó la información para luego clasificar las unidades que pertenecían a un mismo tópico por medio de la codificación abierta, posteriormente se identificaron 
categorías y subcategorías. Finalmente, la evaluación del conocimiento adquirido se hizo comparando los grupos focales iniciales y finales, en los cuales se utilizaron las mismas preguntas.

\section{Declaración sobre aspectos éticos}

La investigación respetó la Declaración de Helsinki, se clasificó como un estudio de riesgo mínimo según la resolución 8430 de 1993 del Ministerio de Salud de Colombia y fue avalada por el Comité de Ética en Investigación de la Fundación Universitaria Autónoma de las Américas.

\section{RESULTADOS}

Las categorías en las que se presentan los resultados están organizadas de acuerdo con las fases del método, de manera que se evidencia el antes, durante y después de las estrategias lúdicas. Cada encuentro finalizó con actividades de monitoreo, lo que facilitó a cada persona hacer un repaso de lo aprendido. Es importante aclarar que en la institución educativa no se estaba desarrollando algún proyecto de salud al momento de la realización de la investigación. Se precisa que en el análisis no surgieron categorías emergentes, en la tabla 1 se muestran las categorías y subcategorías usadas.

Tabla 1. Categorías y subcategorías de análisis de las cuatro fases metodológicas.

\begin{tabular}{|c|c|c|}
\hline Categoría & Subcategorías & Códigos \\
\hline Conocimiento inicial & $\begin{array}{l}\text { Enfermedades de Transmisión Sexual. } \\
\text { Virus del Papiloma Humano. }\end{array}$ & $\begin{array}{l}\text { Contagio y transmisión de ETS. } \\
\text { Formas de protección. } \\
\text { Uso del preservativo masculino. } \\
\text { Factores de riesgo para contraer una ETS. } \\
\text { Transmisión del VPH. } \\
\text { Manifestaciones del VPH. } \\
\text { Vacuna contra el VPH. }\end{array}$ \\
\hline Estrategias lúdicas & Estrategias lúdicas & $\begin{array}{l}\text { Propuestas de los estudiantes sobre } \\
\text { actividades y metodologías. } \\
\text { Formas en las que aprenden más fácil. } \\
\text { Involucramiento en el diseño de las } \\
\text { actividades. } \\
\text { Opiniones, reacciones y aceptabilidad de } \\
\text { las lúdicas implementadas. }\end{array}$ \\
\hline $\begin{array}{l}\text { Conocimiento } \\
\text { adquirido }\end{array}$ & $\begin{array}{l}\text { Enfermedades de Transmisión Sexual. } \\
\text { Virus del Papiloma Humano. } \\
\text { Estrategias lúdicas. }\end{array}$ & $\begin{array}{l}\text { Qué es una ETS. } \\
\text { Formas de transmisión. } \\
\text { Medios de protección. } \\
\text { Qué es el VPH y cómo se transmite. } \\
\text { Manifestaciones clínicas del VPH. } \\
\text { Cómo se previene el VPH. } \\
\text { Asociación del VPH con el cáncer. } \\
\text { La vacuna contra el VPH. }\end{array}$ \\
\hline
\end{tabular}




\section{Fase I) Conocimiento inicial}

En el grupo focal inicial se hizo una exploración de los saberes previos de los participantes con preguntas abiertas acerca del VPH y la vacuna. A partir del análisis de las respuestas se determinó que el conocimiento previo sobre ETS, $\mathrm{VPH}$ y la vacuna y su asociación con el cáncer era bajo. A continuación, se muestran las categorías de análisis:

Enfermedades de trasmisión sexual: algunos de los participantes tienen claro que las ETS se contagian al tener relaciones sexuales sin el uso del preservativo, pero también manifestaron que se puede trasmitir por medio de transfusiones sanguíneas y al usar jeringas contaminadas. Dos de los estudiantes creen que por medio de los estornudos o los besos es posible infectarse de una ETS. La mayoría ha escuchado hablar de las ETS en sus hogares principalmente por parte de las figuras femeninas y expresaron que la única manera para protegerse tanto de las infecciones como de los embarazos no deseados es usando adecuadamente el preservativo. También es importante mencionar que los hombres reconocen que la historia sexual de su pareja es un factor de riesgo para contraer infecciones, al tiempo manifestaron que si su pareja nunca había tenido contacto sexual, no tenían inconveniente para tener relaciones sin el uso del preservativo. Los hombres reconocen la necesidad de realizarse exámenes médicos periódicamente y son enfáticos en que deben conocer a la persona con la que van a tener sexo. Las mujeres, si bien estuvieron de acuerdo con lo dicho por los varones, mantienen una postura tímida al momento de hablar sobre el tema.

Estas son algunas expresiones de los participantes (se omite los nombres de los estudiantes y se asigna un código a cada uno de ellos):
(E1): "Cuando uno va tener relaciones, mirar con qué persona está, porque uno no sabe con quién más ha podido estar, hacerse exámenes"

(E2): [Cómo protegerse de las ETS] "con el preservativo, como hacerse cosas, exámenes, yendo al médico"

Virus del Papiloma Humano: los participantes tienen poca información sobre esta enfermedad, no han recibido educación en sus hogares ni en el colegio, tampoco en jornadas de vacunación realizadas en la institución educativa. Una de las estudiantes cree que la vacuna de prevención para el VPH también sirve como método de planificación. Desconocen las diferentes formas de transmisión, a quiénes afecta, manifestaciones clínicas y la asociación con el cáncer.

(E3): "Uno lo tiene en el estómago y de ahí se le transmite a las mujeres"

(E4): "Es un como un cáncer que le da a la mujer en seno"

(E2): "Yo nunca he escuchado hablar de eso del virus del papiloma en el hombre"

Haciendo alusión a la vacuna mencionan:

(E4): "Sirve para prevenir esa enfermedad"

(E5): "Son tres vacunas"

(E6): "A nosotros solo nos llamaron y nos aplicaron eso y ya"

Es relevante mencionar que al comienzo del grupo focal los estudiantes preguntaron si la información que se iba a compartir sería confi- 
dencial, ante lo cual las investigadoras asintieron. En igual sentido los adolescentes concertaron un pacto verbal para guardar en secreto todo lo que se expresara, no solo en esta discusión sino durante el desarrollo del proyecto. Este acuerdo fue trascendental para que ellos se sintieran confiados para manifestar opiniones, experiencias e inquietudes sin temor a que otros pudieran enterarse o a que fueran juzgados u objeto de burla.

En este encuentro, los que se mostraron más extrovertidos fueron los adolescentes mayores, quienes habían iniciado su vida sexual y contaron algunas de sus experiencias. Los demás revelaron cierta timidez, por lo que la moderadora dirigió algunas preguntas para conocer igualmente sus opiniones. En el grupo focal fue permitido hablar de otros asuntos que emergieron, así, algunos mencionaron temas como otras ETS y el consumo de sustancias psicoactivas. Esto demuestra la necesidad de abordar otras cuestiones que preocupan a los estudiantes y que hacen parte de su cotidianidad.

De otra parte, los participantes manifestaron la expectativa ante el proyecto y demostraron plena confianza hacia las investigadoras. Al terminar la sesión propusieron dividir al grupo en dos para juntarse con los pares más cercanos y desarrollar de esa manera todas las actividades.

\section{Fases II y III) Estrategias lúdicas}

Los estudiantes y las investigadoras diseñaron e implementaron siete estrategias, las propuestas de los estudiantes en la fase II y durante los encuentros de la fase III consistieron en el uso de imágenes, videos, dibujos, diapositivas, juegos con balones y actividades fuera del aula.

En la primera actividad lúdica se explicó la anatomía de órganos reproductores femeninos y masculinos por medio de materiales didácticos e imágenes. Los estudiantes dibujaron en plie- gos de cartulina una silueta de una mujer y un hombre, los pegaron en el tablero y luego vendaron los ojos a algunos de los participantes para que ubicaran las partes del cuerpo en el lugar correspondiente guiados por las voces de sus compañeros (juego que tradicionalmente se conoce como "ponerle la cola al burro").

La segunda actividad se centró en las ETS y sus manifestaciones clínicas por medio de un video animado y una presentación con diapositivas. Se llevaron imágenes impresas sobre las manifestaciones clínicas para que los participantes las asociaran a la enfermedad correspondiente. Para la tercera sesión de trabajo se conformaron cuatro subgrupos, cada uno elaboró el material de un rompecabezas acerca de las manifestaciones clínicas de VPH, posteriormente cada subgrupo armó un rompecabezas diferente al que diseñó.

En el cuarto taller se trabajó en dos equipos y se realizó un juego de preguntas y respuestas con las que se evaluaron los conocimientos adquiridos hasta el momento y se abordó el tema del VPH y su relación con el cáncer de cuello uterino, vagina, ano y orofaringe. Cada participante tomó una cartulina en la que se había escrito una pregunta y sus compañeros de equipo debían dar la respuesta correcta, los estudiantes contaban con ayudas como la llamada a un amigo, cambio de pregunta y eliminar dos de las alternativas incorrectas.

La quinta estrategia estaba dirigida a aprender a identificar los factores de riesgo para contraer el VPH para la cual se propuso una carrera popularmente conocida como "encostalados"; los integrantes de cada grupo debían correr en costales hasta llegar al extremo contrario de la cancha donde estaban ubicados unos baldes que contenían las imágenes de los factores de riesgo $\mathrm{y}$ otras que funcionaban como distractores; el equipo que logró identificarlos y socializarlos fue el ganador. 
En el sexto taller se abordaron las creencias sobre la vacuna, al inicio de la sesión los estudiantes depositaron en una bolsa plástica las preguntas que tenían acerca del tema. Posteriormente, los participantes organizados en un círculo debían pasar entre ellos un balón de fútbol solo con los pies y el participante que dejara caer la pelota debía dar respuesta a una pregunta formulada por alguno de sus compañeros.

La séptima actividad consistió en la búsqueda de un tesoro por medio de pistas en tres estaciones, en las que se entregó información acerca de factores protectores y de riesgo para adquirir el VPH. Los estudiantes debían responder a las preguntas de cada base y pasar a la siguiente. Al final del recorrido cada grupo debía explicar a sus compañeros los factores que le correspondieron en cada estación para acceder a un código con el cual se abría una caja fuerte y se hacían acreedores al tesoro.

Es de resaltar que los encuentros semanales fueron importantes para generar lazos de confianza cada vez más fuertes, al punto que en la tercera sesión fue evidente el compromiso de todos. Además, cada encuentro aumentó el nivel de participación, incluso de los más tímidos. Los adolescentes fueron enfáticos en solicitar que se incluyera el fútbol en las actividades, razón que motivó a crear juegos relacionados con este deporte. Ellos, al ver que sus ideas fueron incorporadas a las estrategias lúdicas, participaron con mayor ahínco y manifestaron sentirse incluidos. En este sentido, en múltiples ocasiones expresaron que estas iniciativas las disfrutaron porque se les preguntaba qué querían hacer, qué les había pasado en experiencias previas y qué pensaban sobre diversos temas, es decir, sus voces fueron escuchadas.

Finalmente, las interacciones en los sucesivos encuentros generaron vínculos afectivos entre pares, así, el proyecto se convirtió en un espa- cio para compartir intimidades y dudas, lo que les permitió sentirse cómodos y dispuestos para el aprendizaje. Además, todas las actividades tuvieron alta aceptación por parte de los participantes. Algunos manifestaron que al inicio esperaban que solo fueran talleres para escapar de clase y no imaginaron que con el juego pudieran aprender. Por otro lado, la edad de las investigadoras también facilitó la cercanía con los adolescentes e incluso al finalizar las lúdicas algunos de ellos se acercaron para solicitar orientación sobre aspectos de su vida sexual.

\section{Fase IV) Evaluación de resultados sobre el conocimiento adquirido}

Los participantes en el grupo focal final fueron más participativos que en el inicial y hablaron con propiedad de los temas tratados; también sucedió que quienes en el inicio fueron más reservados, finalmente expresaron con más confianza sus puntos de vista sin plegarse a los mayores o más experimentados. Se evidenció un proceso reflexivo frente al nuevo conocimiento lo cual permitió que al momento de realizar el conversatorio final expresaran fácilmente conceptos acerca de qué es el VPH, cómo se transmite, cómo se previene y su asociación con el cáncer, entre otros. A continuación, se muestran las categorías de análisis:

Enfermedades de trasmisión sexual: los estudiantes definieron de manera adecuada qué es una ETS, medios de trasmisión y cuál es el único método que los protege de estas.

(E1): [Las ETS] "son infecciones que se transmiten de una persona a otra"

(E8): "se trasmite por sexo normal, anal, oral y por no usar condón"

Virus del Papiloma Humano: los conocimientos de los estudiantes fueron acertados, expre- 
saron el concepto, quién trasmite el virus, las manifestaciones clínicas, la importancia de la vacuna como método de prevención y su relación con el CCU que se desarrolla a partir de esta enfermedad.

(E2): "Pues es una enfermedad de transmisión sexual y la tienen los hombres y se la transmiten a las mujeres y da cáncer de cuello uterino"

(E8): "Eso lo producen son los hombres y que a ellas les puede dar tanto como a los hombres también. Que también existe la vacuna para evitar eso"

Estrategias lúdicas: los participantes reconocieron el uso de la lúdica como parte esencial de su aprendizaje, ya que se divirtieron y las actividades fueron de su interés, además afirmaron no sentirse cohibidos, ni presionados. Lograron hacer una comparación entre la información previa y la que tenían al finalizar el proyecto respecto a los temas tratados en cada sesión; una muestra de ello se refleja en las siguientes expresiones:

(E9): “A mí me gustó porque con el juego uno aprende cosas, tiene más conocimiento de las enfermedades"

(E5): "Me pareció muy chévere, aprendí a cómo cuidarme para que no me pase eso a mí como le ha pasado a otros"

(E2): "Me sentí muy bien, eso me enseña muchas cosas: a prevenir la enfermedad, a tener cuidado con todo eso, con las enfermedades de trasmisión sexual"

De acuerdo con las respuestas iniciales y finales los adolescentes aumentaron notoriamente los conocimientos acerca de los temas abordados por medio de las estrategias lúdicas.
Otro aspecto importante fue la mención de los estudiantes sobre la falta de preparación de los docentes a la hora de explicar los temas relacionados con las ETS, referían que las clases habituales eran monótonas porque se dedicaban a leer y resolver talleres, lo que para ellos no genera ningún tipo de interés.

En suma, las estrategias lúdicas fueron una herramienta que permitió no solo articular la teoría con el juego, sino que generó espacios para una intervención cognitivo-afectiva que posibilitó la apertura de los adolescentes hacia el abordaje de temas sensibles afines a sus intereses, alejados de la visión adultocéntrica. Asimismo, la metodología participativa facilitó que las propuestas de ellos pudieran incorporarse en el diseño de las actividades, para que se ajustaran a sus gustos y necesidades, lo cual demuestra que tanto las emociones como el cuerpo deben ser involucrados en procesos educativos referidos a este grupo poblacional.

\section{DISCUSIÓN}

Al inicio de esta investigación los adolescentes tenían poco conocimiento acerca de ETS, formas de trasmisión, manifestaciones clínicas y prevención, además la mayoría desconocía la asociación de las patologías con su cuadro clínico característico. Otras investigaciones reportan resultados similares, en Cuba ${ }^{15}$ se evidenció insuficiente conocimiento sobre síntomas de ETS, además, poca percepción del riesgo de los adolescentes respecto a sus conductas; Castro et $a l^{7}$ encontraron que las mujeres tenían mayor conocimiento que los hombres sobre el tema, aunque en ambos grupos el conocimiento sobre las manifestaciones clínicas era bajo y presentaban prácticas sexuales de riesgo.

Con relación a las ETS se observó que los hombres poseen mayor conocimiento que las mujeres 
en cuanto a tipos y formas de prevención, pero respecto a manifestaciones clínicas ambos grupos tenían bajo conocimiento. Esto se puede explicar dado el contexto cultural dominado por la cultura patriarcal en la que aún existen tabúes sobre estos temas. Los resultados son similares a los hallados por Barnack et al $^{16}$, quienes encontraron barreras culturales asociadas a creencias tradicionales.

Respecto al VPH se encontró desconocimiento de las características del virus, manifestaciones clínicas y factores de riesgo, mientras que frente a su prevención tenían claridad sobre la necesidad del uso del preservativo masculino, aunque desconocían el condón femenino como método de barrera. Resultados similares hallaron en dos investigaciones en Malasia ${ }^{17,18}$ en las que se encontró que los estudiantes desconocían la clínica, manejo y tratamiento de la infección y como consecuencia se mantenían inadvertidos ante la importancia del contagio y desinteresados para buscar información. En Chile y Colombia se encontró que la mayoría de los adolescentes conocen el condón, aunque le dan uso ocasional durante el acto sexual, además reconocen el preservativo como una herramienta de protección frente al $\mathrm{VPH}^{19,20}$.

La poca información de los adolescentes frente a la asociación de cáncer y VPH lo transforma en un problema de salud pública. Rashwan et al ${ }^{18}$ reportaron que los estudiantes tenían bajo conocimiento sobre CCU y la aceptación de la vacuna contra el VPH. Al respecto se encuentran resultados similares en tres estudios, uno realizado en Chile $^{19}$ y los otros en España ${ }^{21}$ y Colombia ${ }^{22}$ según los cuales las adolescentes conocían poco la relación entre VPH con el CCU y la forma de transmisión, y tenían total desconocimiento de la vacuna o presentaban información errónea sobre ella.

Por otro lado, en este estudio se encontró que la mayoría de los estudiantes ya habían iniciado su vida sexual, razón que refuerza el argumento de dar atención específica y prioritaria a este grupo poblacional, toda vez que el inicio temprano de relaciones sexuales constituye uno de los principales factores de riesgo para adquirir una ETS. De manera que se deben reforzar las actividades de educación para la salud dirigidas a profesores, padres de familia, estudiantes y profesionales de la salud, para que los adolescentes puedan disfrutar de su sexualidad de forma placentera y segura, en ejercicio de sus derechos sexuales y reproductivos.

En esta investigación, durante las interacciones con los participantes, se pudo percibir en el desarrollo de los talleres pedagógicos que las principales fuentes de información fueron la televisión, Internet, los amigos y, para algunos, los padres de familia, principalmente la figura materna; igualmente se evidenció que los docentes y personal de salud no eran referentes. Estos resultados constituyen una limitante pues los adolescentes no tienen acceso a información científicamente válida y carecen de espacios para aclarar dudas y hablar abiertamente del tema, lo que coincide con el estudio de Castro et $a l^{22}$. Así entonces, la preparación de la estrategia educativa aplicada en esta investigación, acorde con los conocimientos previos de los estudiantes y con su contexto sociocultural, demuestra la necesidad de acondicionar las metodologías y la información que es suministrada para lograr un resultado positivo de acuerdo con el entorno particular de acción, lo que se facilita con el enfoque cualitativo escogido.

En el caso de los escolares vinculados a este proyecto, la escuela es un espacio fundamental pues, al encontrarse situados en zona semirural, es la institución de la que se espera se imparta información confiable, ya que está llamada a convertirse en el lugar donde se construya conocimiento que impacte la vida cotidiana de los adolescentes. Así lo corroboran Concha et $a l^{23}$, en el artículo 
de revisión en el que concluyen que las intervenciones educativas dependen de factores como el respaldo político-legislativo del país, el contexto sociocultural, familiar y, en general, del colegio, el cual debe aportar significativamente en la capacitación de docentes en este tipo de temas y en la orientación de estrategias educativas con principios de aprendizaje social.

En esta investigación se demostró que la efectividad de la intervención está ligada a la adaptación cultural de esta. En la literatura se encuentran ejemplos de ello a partir varias metodologías; sin embargo, pocas promueven la participación activa como las desarrolladas en $\mathrm{Cuba}^{15} \mathrm{y}$ Estados Unidos ${ }^{16}$, aunque se reportan otros estudios realizados en Malasia ${ }^{17}$ y Suecia ${ }^{24}$. Por otro lado, algunos trabajos resaltan la efectividad de llevar a cabo intervenciones con base comunitaria y/o que incluyan a padres y madres de familia para que el conocimiento sobre el VPH y la aceptación de la vacuna mejoren ${ }^{16,25}$. Además, Kollar y Kahn ${ }^{26}$ plantean la necesidad de que las estrategias educativas sean apropiadas a la etapa cognitiva y al desarrollo psicosocial de los participantes, que se combine la entrega de información con las oportunidades de desarrollo de habilidades, y que se equilibre la privacidad con la participación de los padres.

Así, la educación para la salud se constituye en una práctica social concreta que busca la autonomía en salud de individuos, familias y comunidades, a través de la combinación de actividades de información y de educación ${ }^{27,28}$. Además, es una iniciativa que vincula a docentes, profesionales en salud y a la comunidad en general, y pretende que los mensajes educativos lleguen a todas las partes involucradas; por consiguiente, las estrategias de educación para la salud generan espacios de discusión, tienen en cuenta las opiniones de todos los actores y promueven la participación activa ${ }^{29}$.

\section{CONCLUSIÓN}

Las estrategias lúdicas permitieron que los adolescentes generaran nuevo conocimiento por medio de un proceso de interiorización y reflexión sobre el VPH y la vacuna. La participación fue el pilar fundamental en esta investigación que partió del saber previo e inquietudes de los estudiantes para desarrollar un proceso de aprendizaje-educación ajustado a las necesidades de la comunidad en el cual se promovió la autonomía. De esta forma, los adolescentes fueron considerados como sujetos y no objetos de intervención.

Se presentaron resultados positivos, los estudiantes lograron hacer una comparación entre la información previa y los aprendizajes durante el desarrollo del proyecto. Además, reconocieron el uso de la metodología lúdica como parte esencial de su aprendizaje y al final de la intervención narraron con claridad conceptos como ETS, VPH, factores de riesgo, factores protectores y manifestaciones clínicas del VPH.

Es importante incluir este tipo de estrategias en la educación para la salud, pues es necesario desarrollar intervenciones de acuerdo con las necesidades y nivel de desarrollo cognitivo y psicosocial de los participantes, que tengan en cuenta el contexto sociocultural de acción. En este sentido, la lúdica potencia los procesos y los conecta no solo con la razón sino con la emocionalidad y el afecto, de tal forma que los adolescentes alcanzan más apertura y disposición para el aprendizaje.

\section{DECLARACIÓN SOBRE CONFLICTOS DE INTERESES}

Los autores no reportan conflictos a declarar relacionados con la presente investigación. 


\section{REFERENCIAS BIBLIOGRÁFICAS}

1. Rodríguez-Jímenez MJ. Protocolo diagnóstico y terapéutico de las infecciones de transmisión sexual en la adolescencia. Medicine [revista en la Internet]. 2014 [citado 2015 Oct 23]; 11(61): 3622-3626. Disponible en: http://dialnet. unirioja.es/servlet/articulo?codigo $=4881844$

2. Fondo de las Naciones Unidas para la Infancia (Unicef). Estado mundial de la infancia. La adolescencia una época de oportunidades. Nueva York: Unicef; 2011. Report No: 148. Disponible en: http://www.unicef.org/ecuador/SOWC2011-Main-Report_SP_02092011.pdf

3. Vargas-Trujillo E, Cortés D, Gallego JM, Maldonado D, Ibarra MC. Estudio a profundidad basado en las Encuestas Nacionales de Demografía y Salud ENDS 1990-2010. Educación sexual de mujeres colombianas en la juventud: un análisis desde el enfoque basado en los derechos humanos. Bogotá: Universidad de los Andes, Universidad del Rosario; 2013.

4. Organización Mundial de la Salud (OMS). Infecciones de transmisión sexual. Nota descriptiva; 2016. Disponible en: http://www. who.int/mediacentre/factsheets/fs110/es/

5. Silva-Fohn J, Andrade-Iraola K, Palacios-Vallejos E, Rojas-Huayta V, Mendonza-Júnior J. Nivel de conocimientos y comportamientos de riesgo relacionados con infecciones de transmisión sexual entre adolescentes mujeres. Enfermería Universitaria [revista en la Internet]. 2014 [citado 2015 Oct 09]; 11(4): 139-144. Disponible en: http://www.sciencedirect.com/science/article/ pii/S1665706314709261

6. Ministerio de Salud y la Protección Social de Colombia, Profamilia, Organización Internacional paralas Migraciones(OIM) y Fondo de Población de las Naciones Unidas (UNFPA).
Política nacional de sexualidad, derechos sexuales y derechos reproductivos. Colombia; 2010. Disponible en: https://www.minsalud. gov.co/sites/rid/Lists/BibliotecaDigital/RIDE/ DE/LIBRO\%20POLITICA \%20SEXUAL\%20 SEPT\%2010.pdf

7. Castro-Abreu I, Rizo-Montero Y, Reyes-Pelier Y, Vásques-Adán Y. Intervención educativa sobre infecciones de transmisión sexual en adolescentes de la secundaria Fructuoso Rodríguez. Revista Habanera de Ciencias Médicas [revista en la Internet]. 2012 [citado 2015 Oct 05]; 11(2): 300-307. Disponible en: http://scielo.sld.cu/pdf/ $\mathrm{rhcm} / \mathrm{v} 11 \mathrm{n} 2 / \mathrm{rhcm} 15212 . \mathrm{pdf}$

8. Ortíz-Sánchez NL, Rodríguez-González DA, Vázquez-Lugo M, Álvarez-Aragón M, SánchezUrra L. Intervención educativa sobre infecciones de transmisión sexual en adolescentes. Rev.Med. Electrón [revista en la Internet]. 2015 [citado 2017 Sep 09]; 37 (5): 418-429. Disponible en: http://scielo.sld.cu/scielo.php?script=sci_arttext \&pid=S1684-18242015000500002

9. Barnack-Tavlaris JL, Garcini L, Sánchez O, Hernández I, Navarro AM. Focus Group Discussions in Community-Based Participatory Research to Inform the Development of a Human Papillomavirus (HPV) Educational Intervention for Latinas in San Diego. J Cancer Educ. [revista en la Internet]. 2013 [citado 2017 Oct 07]; 28(4): 1-10. Disponible en: https://www.ncbi.nlm.nih. gov/pmc/articles/PMC3867936/

10. Kwang NB, Mahayudin T, Yien HL, Abdul Karim AK, Teik CK, Shan LP. Effect of an Educational Intervention on Knowledge of Human Papillomavirus Vaccination among PreUniversity Students in Malaysia. Asian Pac J Cancer Prev [revista en la Internet]. 2016 [citado 2017 Nov 08]; 17(1): 267-274. Disponible en: http://journal.waocp.org/?sid=Entrez:PubMed\& id=pmid:26838222\&key=2016.17.1.267 
11. Rashwan H, Lubis SH, Ni KA. Knowledge of Cervical Cancer and Acceptance of HPV Vaccination among Secondary School Students in Sarawak, Malaysia. Asian Pac J Cancer Prev [revista en la Internet]. 2011 [citado 2017 Dic 01]; 12(7): 1837-1841. Disponible en: https://www.researchgate. net/publication/51839402_Knowledge_of_ Cervical_Cancer_and_Acceptance_of_HPV_ Vaccination_among_Secondary_School_ Students_in_Sarawak_Malaysi

12. Urrutia MT, Concha X, Riquelme G, Padilla O. Conocimientos y conductas preventivas sobre cáncer cérvico-uterino y virus papiloma humano en un grupo de adolescentes chilenas. Rev. chil. nfectol. [revista en la Internet]. 2012 [citado 2016 Sep 27]; 29(6): 600-606. Disponible en: http:// www.scielo.cl/scielo.php?script=sci_arttext\&pi $\mathrm{d}=$ S0716-10182012000700003

13. Rengifo-Reina HA, Córdoba-Espinal A, SerranoRodríguez M. Conocimientos y prácticas en salud sexual y reproductiva de adolescentes escolares en un municipio colombiano. Rev. salud pública [revista en la Internet]. 2012 [citado 2015 Oct 11]; 14(4): 558-569. Disponible en: http://www. redalyc.org/pdf/422/42226912002.pdf

14. Camaño-Puig R, Sanchis-Martínez MM. Vacuna contra el virus del papiloma humano en adolescentes: Análisis mediante grupos focales. Rev. salud pública [revista en la Internet]. 2014 [citado 2017 Jul 20]; 16(5): 647-659. Disponible en: https://revistas.unal.edu.co/index.php/ revsaludpublica/article/view/41021/51509

15. Castro-Reyes EM, Miranda-Machado PA, Borre-Arrieta O. Conocimientos, actitudes y prácticas acerca del virus del papiloma humano en adolescentes escolarizados. Revista Ciencias Biomédicas [revista en la Internet]. 2012 [citado 2016 Oct 25]; 3(2): 275-281. Disponible en: http://www.revista.cartagenamorros.com/pdf/32/13PAPILOMA.pdf
16. Concha X, Urrutia MT, Araya AX. Prevención de cáncer cérvicouterino: ¿qué nos señala la literatura en relación a la educación dirigida a los profesores de educación básica/media?. Rev. chil. obstet. ginecol. [revista en la Internet]. 2013 [citado 2017 dic 02 ]; 78(3): 187-192. Disponible en: http://www.scielo. cl/scielo.php?script $=$ sci_arttext $\&$ pid $=$ S071775262013000300004\&lng=es

17. Grandahl M, Rosenblad A, Stenhammar C, Tyden T, Westerling R, Larsson $\mathrm{M}$, et al. School-based intervention for the prevention of HPV among adolescents: a cluster randomised controlled study. BMJ Open [revista en la Internet]. 2016 [citado 2017 Dic 01]; 6: 1-11. Disponible en: http://bmjopen.bmj.com/content/6/1/e009875. full

18. Ito T, Takenoshita $R$, Narumoto $K$, Plegue $M$, Sen A, Crabtree BF, et al. A community-based intervention in middle schools to improve HPV vaccination and cervical cancer screening in Japan. Asia Pacific Family Medicine [revista en la Internet]. 2014 [citado 2017 nov 20]; 13:1-8. Disponible en: https://www.ncbi.nlm.nih.gov/ pmc/articles/PMC4245727/pdf/12930_2014_ Article_13.pdf

19. Kollar LM, Kahn JA. Education about human papillomavirus and human papillomavirus vaccinesin adolescents. CurrOpin Obstet Gynecol [revista en la Internet]. 2008 [citado 2016 Jul 23]; 20(5): 479-483. Disponible en: http://journals. lww.com/co-obgyn/Abstract/2008/10000/ Education_about_human_papillomavirus_and_ human.9.aspx

20. De Vincezi A, Tudesco F. La educación como proceso de mejoramiento de la calidad de vida de los individuos y de la comunidad. Revista Iberoamericana de Educación [revista en la Internet]. 2009 [citado 2016 Jul 21]; 49(7): 1-12. Disponible en: https://dialnet.unirioja.es/servlet/ articulo? codigo $=3116567$ 
Estrategias lúdicas para aumentar el conocimiento de un grupo de adolescentes sobre el virus del papiloma humano

21. Organización Mundial de la Salud (OMS). Educación para la salud: Manual sobre educación sanitaria en atención primaria de salud. Ginebra; 1989. Disponible en: http://apps.who.int/iris/ handle/10665/38660
22. Sanabria-RamosG. Eldebateen tornoala Promoción de Salud y la Educación para la Salud. Revista Cubana de Salud Pública [revista en la Internet]. 2007 [citado 2016 Feb 22]; 33(2). Disponible en: http://www. redalyc.org/articulo.oa?id=21433204 